\title{
TRANSPORT OF DANGEROUS GOODS AS PART OF A FUNCTIONAL MODERN SOCIETY
}

\author{
Petya Vaskova Hristova ${ }^{1}$
}

\begin{abstract}
The European economy is dependent on transport. Electronics, fertilizer, medical items, metal paint, plastic, rubber and different modes of machinery are classified as dangerous goods when transported, as are pesticides and different products for agriculture and cosmetics. Within the transport context, dangerous goods are considered to be those goods which may cause harm to people, the environment or property. They are transported mainly by specialized companies, using special equipment. It is vitally important for the economy that dangerous goods are transported in a well-synchronized logistic chain that is both functioning and efficient. The transport often requires the use of different transport modes, intermediate storing or crossing of national borders. In order to ensure that the complex chain is efficiently functioning, the following article aims to summarize the harmonization and bridge the differences between the nation's legislations and those governing the various modes of transport. Innovative technical tools, methods, and systems are analyzed in cooperation with operators and infrastructure managers. The article describes how the economy is highly influenced by safety regulations and anti-terror actions.
\end{abstract}

UDC Classification number: 338.2; DOI: http://dx.doi.org/10.12955/cbup.v5.922

JEL Classification: L92

Keywords: dangerous, goods, environment, economy, safety, efficient

\section{Introduction}

The European transport policy is obligatory for all European countries and regulates important issues such as traffic jams, safety issues, security, prevention measures and environmental protection. Within that European transport policy, a strict finance framework for infrastructure projects has been developed. One of the most important ones is for transport.

In the past ten years, the European Union has witnessed a dramatic growth in the importance of advanced industrial societies, namely regulation and risk assessment, as well as innovations. The use of law to regulate economic activities has become a defining characteristic of the modern society. Managing the entire logistic chain well and efficiently is crucial for the transport of dangerous goods.

\section{Transport of dangerous goods as a part of a modern society}

Dangerous goods are considered as dangerous because during their transport they may cause harm to people, the environment or property through being explosive, flammable, radioactive, toxic, oxidative, corrosive or some other chemical property. The legislation in force has been extended, and currently, it covers the whole transport chain from sender to hauler till the receiver. They are prohibited to be transported but because we can't live without products that are considered dangerous goods they are transported under strict regulations. Those regulations are precisely written into the Directive 2008/68/EO and its annexes as they are amended.

The dangerous goods are shipped as freight goods accompanied with strict safety and security regulations. In relation to that transport policy, the serious accidents on roads have been reduced by more than $50 \%$ in the last few years. The intelligent transport systems of dangerous goods and the usage of special equipment that allows following the goods during the whole transport time is an outcome of the modern society solutions.

The dangerous goods by themselves rarely cause accidents but, as a coincidence of an accident, they can cause extensive damage. Last year, on $10^{\text {th }}$ December 2016 in the village of Hitrino, Bulgaria, a train of a private railway operator derailed and caused enormous damage to the infrastructure and the environment. 8 inhabitants of the village died, 29 were seriously injured and more than a 100 injured. All of the citizens of Hitrino were evacuated for 10 days due to the heavy air pollution as a result of the accident and the spill of the dangerous goods.

Crucial characteristics for the transport of dangerous goods as a part of the functional modern society is the mobility, petrol dependency, infrastructure, business competency and environmental protection.

According to the Finnish strategy for transport of dangerous goods (2005), the assessment of the transport of dangerous goods as a part of the modern society involves:

${ }^{1}$ Faculty of Transport and Energy, University of National and World Economy, Sofia , Bulgaria, pettivass@aol.com 
1. impact assessment which aims to promote the functionality of logistic chains;

2. safety of transport, the traffic, and environmental protection;

3. assurance that all national specific conditions are duly taken into account at the European and international level;

4. to improve the competitiveness and effectiveness of the field.

The administrative support shall process, plan and monitor the transport of dangerous goods. All personnel involved in such transport should promote safety, among the economic and profitable operators across the entire TDG sector.

One important issue which has been a practice in the last several years within Western European countries is a relevant working time for the people involved in the transport of dangerous goods. The time that the personnel involved in the loading, transport or unloading of dangerous goods, as well as all other related to the transport activities, should have a shortage of the working hours.

As stated into the Directive 2008/68/EO (2008), to improve the wellbeing and working ability of personnel, the expertise in the sector shall be guaranteed in a long term and the personnel to be accordingly trained.

Another example is the transport of medicines, petrol products, plastic, etc.; such products which the modern society can't survive without. That is why from an economic point of view, in the transportation of dangerous goods it is vital that the entire transport chain to be designed in a way that these goods reach their destination on time, safely and profitably.

All regulations are amended in such a way to meet the needs of the industry and at the same time those of the private consumers. Due to social changes nowadays in the EU and the constant increase of the competitive transport market, the stock of kept materials for production has been minimized as much as possible. The success of the companies and operators depends on ensured logistic chains, which are functioning efficiently and safely.

The transport of dangerous goods (TDG) takes place on all roads within Europe and all over the world. Its transport often is international and even with different modes of transport; the TDG rules and regulations have been harmonized and synchronized. For example, the requirements for the road and rail transport and waterways for EU have been issued in one single directive: Directive 2008/68/EO. The Annexes ADR, RID and ADN contain all the important rules for those three modes of transport.

GO GREEN is another important transport policy which is old but at the same time still in its beginning. Go GREEN is an initiative which started several years ago stating that the current transport system comes along with a wide range of problems - such as global warming, environmental degradation, health implications and the emission of gases. It is considered that the transport sector can be attributed for $23 \%$ of the world's gas emissions resulting from the burning of fossil fuels. To reduce the air pollution significantly, an efficient model of optimization for the transport of dangerous goods is required.

All participants in the transport of dangerous goods aim to reach a safe, secure and functional system.

Figure 1 represents a model for a safe and functional transport system within the modern European society.

\section{Guidelines for safe, secure and modern transport of dangerous goods}

According to Tzvetkova (2010), the functionality of the transport of dangerous goods shall be managed by the results. In order to increase the clients' satisfaction from the transport and at the same time to meet the high levels of safety and security, the following guidelines may be summarized:

1. Reduce the quantity and unnecessary volume of paper; transport documentation shall be accurate and clear. The legal requirement and obligations for the participants shall be known and comprehended by all operators and authorities engaged in the surveillance or supervision. The legislation should be clear for everyone, effective and understandable.

2. Advance training and strengthening of the level of knowledge for the transport of dangerous goods. All TDG sector operators should be trained to the level of their responsibilities. This will improve the knowledge and the general safety attitude and improve the safety within the entire transport chain. 


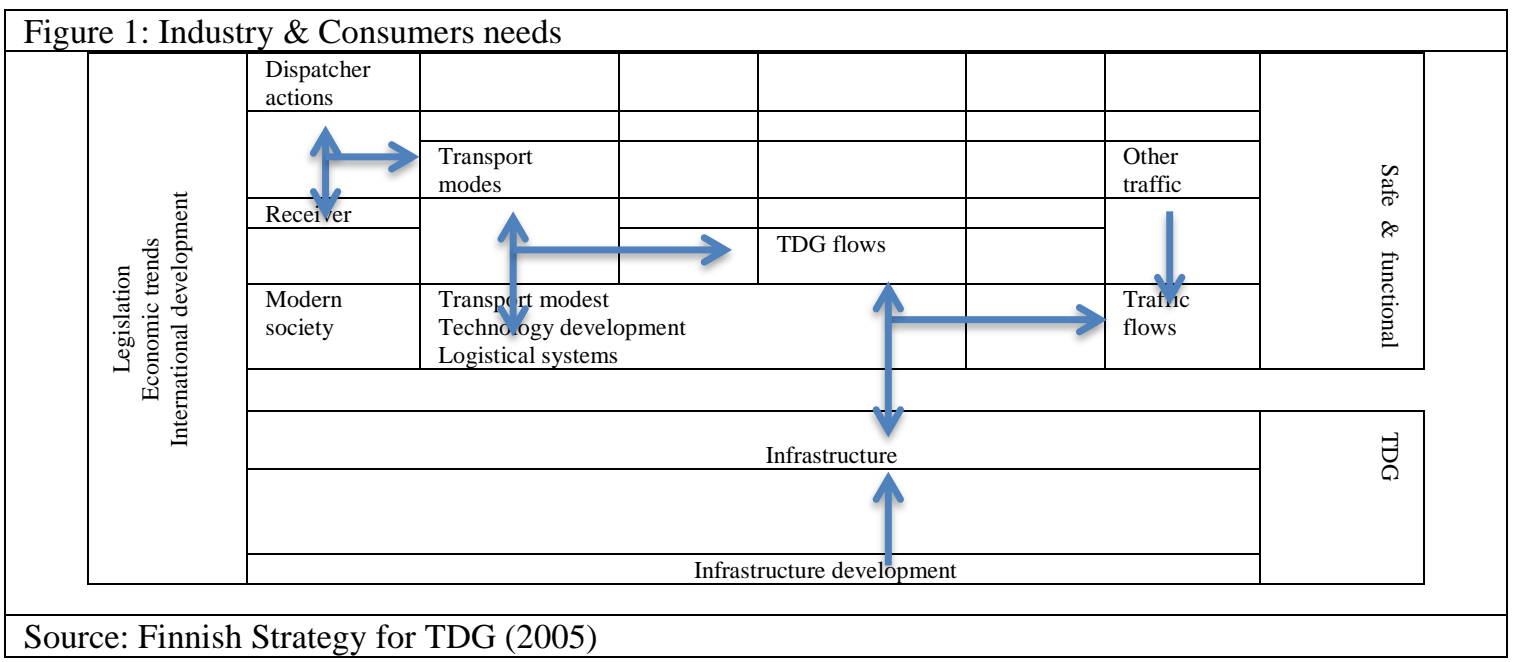

3. Accessible sources of information, free of charge for the consumers and interested parties.

4. Safe and profitable transport through cooperation. In order to achieve the above mentioned goals, the cooperation and open communication between various authorities, administrations, infrastructure managers and operators is a crucial sector indicator. The cooperation should be promoted during the daily work of everyone.

5. Appropriate surveillance and supervision duties.

6. Removal of the level crossings especially on the routes with dangerous goods. TDG routes shall be functional and safe.

\section{Conclusion}

The transport of dangerous goods takes place on roads, railways, by water, and by air. The entire logistic chain is often international. The transport often requires the use of multiple transport modes and the crossing of national borders and well developed logistic chains. In order to ensure that the complex logistic chain is functional, it is believed that, where possible, legislation should be simplified and harmonized. The harmonization of the legislation applies to solve practical issues. Technology and telematics applications are increasingly utilized in TDG. The development and maintenance of the infrastructure and transport routes are ensured and particular attention has been put into the regulations and legislation norms.

The article summarizes the current transport of dangerous goods where the safety is priority number one. Cooperation between the different administrative authorities, the operators and consumers as well as all other relevant participants is essential for promoting safety and environmental protection, but at the same time ensuring an economic efficiency.

\section{References:}

Tzvetkova, S. "Guidelines for improvement the road transport of dangerous goods", KRISAN-S, S., 2010;

Directive 2008/68/EO of the European Parliament and the Council of $24^{\text {th }}$ September 2008 on the inland transport of dangerous goods, 2008;

Finnish strategy for transport of dangerous goods 2005-2015, Finnish Ministry of Transport, 2005; 